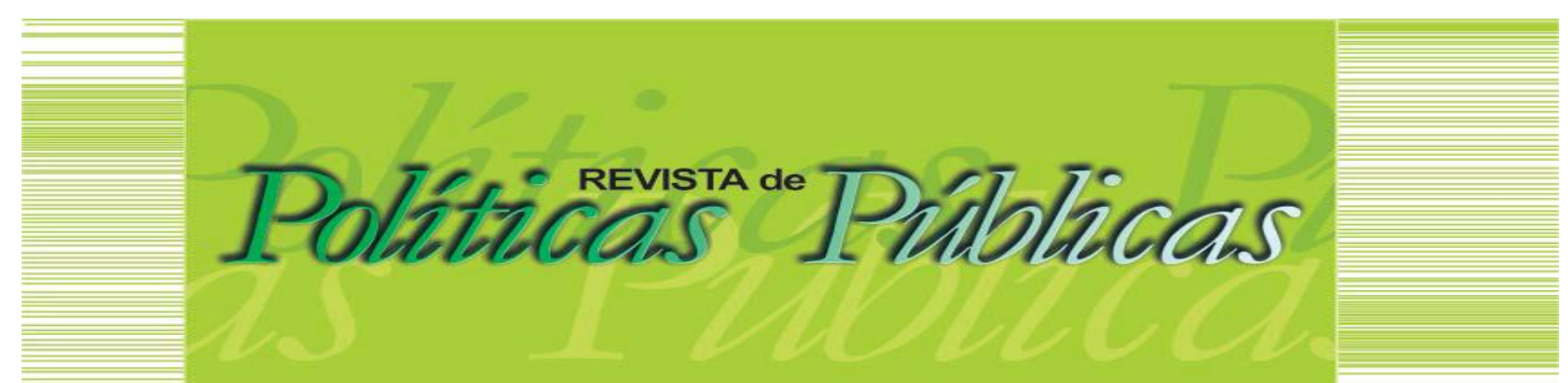

\title{
PLURALISMO JURÍDICO COMO ALTERNATIVA EPISTEMOLÓGICA PARA A CULTURA DE DIREITOS HUMANOS DESDE O CONTEXTO LATINO-AMERICANO
}

\author{
André Luiz Pereira Spinieli ${ }^{1}$
}

\section{Resumo}

O debate sobre o pluralismo jurídico no contexto político e social latino-americano não é recente, de modo que suas percepções foram renovadas a partir do movimento neoconstitucionalista operado no continente, responsável por desencadear alternativas epistêmicas para se pensar a efetividade dos direitos humanos e dos direitos de cidadania, tudo a partir da lógica de emancipação social e descolonialidade, como possibilidade de rompimento com o constitucionalismo tradicional, de cunho conservador, hegemônico e colonialista. Em termos gerais, como uma das respostas à concepção juspositivista, o pluralismo jurídico surge como modelo de pensamento para a práxis dos direitos humanos, em face de uma sociedade na qual impera a lógica das exclusões concretas em contrariedade às inclusões abstratas. Dessa forma, tomando por base a abordagem bibliográfica, este trabalho propõe oferecer reflexões a respeito do atual estado da cultura de direitos humanos instalada na América Latina, com enfoque nas contribuições epistemológicas advindas da teoria crítica dos direitos humanos e do pluralismo jurídico wolkmeriano.

Palavras-chave: Pluralismo jurídico. Direitos humanos. Cultura constitucional. América Latina. Teoria crítica dos direitos humanos.

\section{LEGAL PLURALISM AS AN EPISTEMOLOGICAL ALTERNATIVE FOR THE CULTURE OF HUMAN RIGHTS SINCE THE LATIN AMERICAN CONTEXT}

\begin{abstract}
The debate on legal pluralism in the Latin American political and social context is not recent, so that their perceptions were renewed from the neo-constitutionalist movement operated on the continent, responsible for triggering epistemic alternatives to think about the effectiveness of human rights and human rights of citizenship, all based on the logic of social emancipation and decoloniality, as a possibility of breaking with traditional constitutionalism, of a conservative, hegemonic and colonialist nature. In general terms, as one of the answers to the juspositivist conception, legal pluralism emerges as a model of thought for the practice of human rights, in the face of a society in which the logic of concrete exclusions prevails in opposition to abstract inclusions. Thus, based on the bibliographic approach, this work proposes to offer reflections on the current state of human rights culture in Latin America, focusing on the epistemological contributions arising from the critical theory of human rights and legal Wolkmer's pluralism.
\end{abstract}

Keywords: Legal Pluralism. Human rights. Constitutional culture. Latin America. Critical theory of human rights.

Artigo recebido em: 20/01/2020 Aprovado em: 25/10/2020 DOl: http://dx.doi.org/10.18764/2178-2865.v24n2p653-671.

\footnotetext{
1 Advogado. Mestrando em Direito pelo Programa de Pós-Graduação da Universidade Estadual Paulista (UNESP).. Professor voluntário (estágio-docência) de Regime Internacional de Direitos Humanos no Curso de graduação em Relações Internacionais da Universidade Estadual Paulista (UNESP). Professor de Noções de Administração Pública, Filosofia e Sociologia para carreiras policiais (PMESP e Barro Branco) na Escola Instinto Lógico (IL). E-mail: spinieliandre@gmail.com
} 


\section{INTRODUÇÃO}

A historiografia latino-americana nos permite verificar, de antemão, que a cultura de direitos humanos no continente, à imagem e semelhança de outros elementos, como a própria sistemática social e institucional, tem como origem um construto realizado a partir das visões de mundo dos colonizadores. De forma geral, os atores e as instituições do direito neste continente estão vinculados ao positivismo jurídico herdado dos metropolitanos, que utilizaram a estrutura normativista, estatista, formalista e pós-violatória como instrumento apto à expansão do capitalismo europeu sobre as terras do novo continente.

A ampliação e o enraizamento dos elementos do positivismo jurídico no contexto social latino-americano, teoria na qual a lex sobrepõe o jus, fundamentaram as práticas coloniais de enfraquecimento da população a partir do rompimento com uma cultura própria nascente e em consequente crescimento, impondo-se uma associação da cultura geral e jurídica dos povos nativos aos cânones europeus. Portanto, impôs-se um modelo pré-constituído não apenas de direito, mas também de sociedade, em que a repressão cultural transformou a realidade latino-americana em verdadeiras subculturas camponesas analfabetas, desprovidas de autonomia e padrões específicos de expressão jurídica (QUIJANO, 1992).

A construção de uma cultura jurídica latino-americana essencialmente formalista, de caráter ahistórico, racionalista, positivista e legalista, tem para si a preocupação com as formas e formalidades do direito, mas não com sua realidade prática ou incidência na dinâmica social. $A$ visão positivista que tomou por séculos as sociedades emergentes da América Latina, principalmente até a entrada em vigor das teorias críticas da segunda metade do último século, encontra-se encarcerada em um cativeiro, pelo qual o conhecimento e a cultura de direitos humanos são reduzidos a quatro paradigmas: dois de cunho científico, um político e outro filosófico.

Sob a égide do citado legalismo pós-violatório - cujas ideias foram fixadas fora de lugar, ao ponto de não incorporar os direitos humanos das minorias e grupos vulneráveis latino-americanos nos sistemas jurídicos, por influência do liberalismo econômico e do idealismo jurídico -, 0 neoconstitucionalismo do século XX, tipicamente construído a partir das bases filosóficas da libertação de Ignacio Ellacuría e Enrique Dussel, por exemplo, surge como premissa para se pensar a emancipação social e jurídica dos povos frente ao positivismo. A propósito, esse novo constitucionalismo é preenchido a partir da enorme preocupação com as políticas públicas e a realização dos direitos humanos, em especial os sociais, dos povos latino-americanos, cujas melhores expressões são os documentos constitucionais equatoriano e boliviano, com a noção do bem viver ${ }^{1}$. 


\section{PLURALISMO JURÍDICO COMO ALTERNATIVA EPISTEMOLÓGICA PARA A CULTURA DE DIREITOS HUMANOS DESDE O CONTEXTO LATINO-AMERICANO}

No instante de identificação e intensificação por que passa a luta pelos direitos humanos na América Latina, associados aos preceitos do novo constitucionalismo latino-americano, que escapa às bases eurocêntricas do direito, surgem duas outras premissas válidas para se pensar a cultura jurídica dos povos (des)colonizados: de um lado, a teoria crítica dos direitos humanos e, de outro, o pluralismo jurídico. Assim, os direitos humanos passam a ser objeto da crítica jurídica, devendo ser compreendidos como elementos indispensáveis para o desenvolvimento das sociedades e a quebra das bases jurídicas e políticas positivistas. Dessa forma, ainda que persistam os altos níveis de marginalização, pobreza e discriminação, o desenvolvimento dos direitos humanos nos espaços latinoamericanos ascende sob a forma de crítica, para atestar o abismo existente entre teoria e realização material desses direitos.

$\mathrm{Na}$ outra margem, nunca distante das formulações teóricas da crítica dos direitos humanos, o pluralismo jurídico se revela sob o formato de elemento que tenta descontinuar a lógica constitucional tradicionalista, conservadora, monista e hegemônica levada a cabo pelos colonizadores nos respectivos territórios dominados, como modelo de pensamento sobre os direitos humanos e sua práxis emancipatória, em face de uma sociedade em que impera a razão das exclusões concretas em contrariedade às inclusões abstratas. Adota-se, para os fins deste trabalho, a ideia de pluralismo jurídico pensada a partir das contribuições do professor brasileiro Antônio Carlos Wolkmer, para quem essa nova visão pode ser considerada "a multiplicidade de práticas jurídicas existentes num mesmo espaço sociopolítico, interagida por conflitos ou consensos, podendo ser ou não oficiais e tendo sua razão de ser nas necessidades existenciais, materiais e culturais" (WOLKMER, 2001, p. 219).

No âmbito de uma fundamentação jurídico-filosófica dos direitos humanos, o pluralismo jurídico aparece como verdadeira oposição à concepção de monismo jurídico, para o qual a ideia de direitos humanos está centrada única e exclusivamente no Estado e nos padrões histórica e culturalmente reproduzidos pelas sociedades modernas. É dizer que o pluralismo jurídico rechaça as teses monistas, para as quais há apenas um ordenamento jurídico fundado no direito natural, inserindo no direito as fontes decorrentes das transformações políticas, culturais, sociais e econômicas, que permitem ao homem a adoção de posições que rumam à sua emancipação, como vivente participante dos projetos sociais. No caso latino-americano significa a devolução, pelas vias críticas do direito, de todo um modo autêntico de viver e pensar das classes anteriormente dominadas.

Observando-se a sinergia existente entre os temas em questão para o fim de realização prática dos direitos humanos, a proposta deste trabalho é oferecer reflexões a respeito do atual estado da cultura de direitos instalada na América Latina. Adota-se a concepção de pluralismo jurídico wolkmeriano como marco teórico e, consequentemente, alternativa epistêmica apta não apenas para se pensar novas perspectivas para a efetividade dos direitos humanos e dos direitos de cidadania no 
continente, mas também para firmar a contraposição entre o conservadorismo constitucional colonizador e 0 atual estado de emancipação social e descolonialidade dos grupos sociais latinoamericanos.

\section{BASES EPISTEMOLÓGICAS PARA SE PENSAR OS DIREITOS HUMANOS NA AMÉRICA LATINA}

Historicamente, o pensamento que fundamenta os institutos e o modo de fazer do direito no contexto latino-americano, sobretudo no campo dos direitos humanos, remonta à lógica da conquista ibérica sobre o continente em questão. A missão inicial de dominação foi colocar em prática o processo de supressão das organizações sociais que detinham para si um conjunto de regras plurais, ainda que não consideradas formalmente jurídicas, mas que iam de encontro aos interesses do direito monista e hegemônico que se instalava paulatinamente nas novas terras.

Com intenções de assegurar uma estrutura estatal preponderantemente feudal e patrimonialista, os colonizadores certamente não tinham interesse algum em salvaguardar os direitos e as culturas plurais dos povos nativos do novo continente, senão utilizar as terras e suas riquezas para 0 sustento das cortes reais ibéricas e reduzir a base popular latino-americana à condição de analfabetos jurídicos², tal como inserir - muitas vezes por intermédio da força - a cultura jurídica hegemônica, de caráter puramente juspositivista.

A partir do processo de colonização latino-americana, os ibéricos foram afastados da possibilidade de emancipar sócio e juridicamente os povos aqui encontrados, para introduzir um novo modo de pensar o direito, de acordo com as concepções próprias das metrópoles europeias, eivado de bases rígidas e imutáveis. De fato, o alijamento do pensamento jurídico sobre os direitos humanos nos países que compõem o bloco da América Latina tem como fonte os dois paradigmas hegemônicos do direito desde o tempo da conquista ibérica: o jusnaturalismo e, mais fortemente enraizado, o positivismo jurídico. Conforme Manuel Atienza (2017), a insatisfatória situação da filosofia do direito e dos direitos humanos nos países latino-americanos se deve à insuficiência explicativa da realidade dos povos dominados, transformando a cultura de direitos em meras produções elitistas.

Para além da supressão do direito plural ao tempo da colonização, os ibéricos também foram responsáveis por anestesiar os sensos de luta popular arraigadas entre os povos nativos da América Latina. Isso porque a proposta de um pluralismo jurídico era considerada, aos olhos dos metropolitanos, um contrassenso frente à noção de um direito juspositivista, traduzido em formalismos e burocracias, e de cidadania, como acesso censitário - para homens brancos e proprietários - aos direitos fundamentais. 


\title{
PLURALISMO JURÍDICO COMO ALTERNATIVA EPISTEMOLÓGICA PARA A CULTURA DE DIREITOS HUMANOS DESDE O CONTEXTO LATINO-AMERICANO
}

Conforme Raquel Z. Yrigoyen Fajardo (2011, p. 140):

\begin{abstract}
El pluralismo jurídico, como forma de coexistencia de varios sistemas normativos dentro de un mismo espacio geopolítico, aun en su forma colonial subordinada, no era admisible para la ideología del Estado-nación. El Estado-nación monocultural, el monismo jurídico y un modelo de ciudadanía censitaria (para hombres blancos, propietarios e ilustrados) fueron la columna vertebral del horizonte del constitucionalismo liberal del siglo XIX en Latinoamérica. Un constitucionalismo importado por las elites criollas para configurar estados a su imagen y semejanza, con exclusión de los pueblos originarios, los afrodescendientes, las mujeres y las mayorías subordinadas $[\ldots]^{3}$.
\end{abstract}

Dessa forma, instalava-se e perpetuava-se na América Latina, até os novos horizontes jurídicos e sociais inaugurados pelo constitucionalismo do século $X X$, sobretudo com o México, um verdadeiro pluralismo jurídico conservador, como reflexo de um poder instituinte oligárquico, cuja proposta era a de suspender e destruir os direitos humanos dos povos nativos. Trata-se do retrato posto dos movimentos de conquista praticados pelos Estados-nação europeus em face dos povos latino-americanos, exteriorizando a desregulamentação dos direitos humanos e a desubjetivização dos povos e dos movimentos sociais.

A propósito, a quebra da cidadania do outro e da fruição dos direitos humanos no contexto em comento fica clara ao se afirmar a existência de um projeto crioulo 4 de sujeição dos povos nativos, cujas diretrizes eram: a) converter os latino-americanos em cidadãos titulares de direitos individuais a partir da dissolução de seus direitos clássicos, formulados a partir de um pluralismo, para evitar levantes; b) cristianizar os povos nativos para expandir a sujeição cultural e expandir a mão de obra preponderantemente agrícola; c) estabelecer relações de luta contra os povos dominados - uma espécie de bárbaros - para anexar seus territórios ao do Estado-nação europeu (FAJARDO, 2011, p. 140).

Com o império do positivismo herdado dos colonizadores, pensar os direitos humanos desde o contexto político, jurídico e social latino-americano exige saber que se fala em ausência de direitos, em demandas falhas ou atrasadas e em propostas constitucionais que, além de não serem postas em prática, ocasionam o entorpecimento jurídico dos povos e dá ensejo ao efeito encantatório dos direitos humanos (GALLARDO, 2008). Na América Latina, deve-se falar em direitos humanos a partir de sua negação e do constitucionalismo de ordem juspositivista como mecanismo para a castração de todo o potencial emancipatório que os direitos humanos carregam. Trata-se de uma estrutura de pensamento jurídico que utiliza a não realização desses direitos como instrumento para negar a configuração histórica sociocultural dos povos latino-americanos.

Falar sobre os direitos humanos desde o contexto latino-americano reclama fazer referência à existência de limites estruturais, sociomateriais, epistemológicos e relacionais que fundamentam certa separação entre a teoria e as práticas dos direitos humanos. É dizer: de um lado, 
têm-se direitos encastelados pelos códigos e constituições, formalizados; por outro, uma baixa na prática desses direitos, que não se materializam. Como afirma o professor David Sánchez Rubio (2015, p. 100-101):

Por un lado, estamos de acuerdo con la importancia que tienen los derechos humanos, el efecto positivo y encantador que poseen porque simbólicamente sirven para legitimar la justicia de los estados civilizados, constitucionales y democráticos. Discursivamente casi todo el mundo está convencido de lo necesarios que son para que principios como la dignidad humana, la libertad y la igualdad sean garantizadas en cualquier comunidad que los respeta. Pero por otro lado, somos conscientes de lo difícil que resulta cumplirlos en el día a día, en la práctica y, lo que es peor, que sean garantizados en determinados espacios sociales como puede ser el ámbito doméstico o los mundos de la producción, el trabajo y/o el mercado 5 .

Assim, embora compreendidos como universais, os direitos humanos inseridos na prática latino-americana têm revelado certo grau de relativização, com a consequente impossibilidade de universalização. Nesse ponto, é válido questionar: os direitos humanos são universais para quem (ou para quais grupos)? Isso porque a gênese histórica dos direitos humanos no continente latinoamericano não leva em consideração as reivindicações dos grupos social e historicamente excluídos e marginalizados, ou seja, trata-se de mera transmigração da tradição europeia para a América Latina. Dessa forma, lançando-se olhares sobre a capacidade de exercício dos direitos humanos, embora aplicáveis formalmente a todos os seres humanos, nem todos conseguem exercitá-los.

As taxas de (in)efetividade dos direitos humanos no contexto jurídico e social latinoamericano são bastante altas, ao ponto de, em alguns casos, aniquilar qualquer anseio em termos de realização prática desses direitos. A título exemplificativo, os debates mais incisivos sobre direitos humanos no Brasil, ao ponto de atingir novos setores da sociedade, são recentes e urgentes. Em realidade, passaram ao posto como tema principal nas pautas sociais após o terrorismo de Estado vivenciado ao tempo da ditadura militar e a partir do agravamento das desigualdades sociais no país. Com o movimento de democratização primária na América Latina, houve a consolidação formal dos direitos humanos de primeira dimensão, sem que, por outro lado, as sociedades tenham conseguido avançar em termos de efetividade dos direitos sociais, em grande parte por força da não superação das desigualdades históricas.

Foi apenas na última década que as sociedades latino-americanas conseguiram reinventar os termos de efetividade dos direitos de segunda dimensão, de cunho social, dando nova roupagem ao contexto político e econômico do continente. Essa mudança se deve primordialmente pela ascensão massiva ao poder de governos considerados progressistas e de orientação ideológica de esquerda, cujas propostas de governo estavam calcadas no olhar para a vítima histórica, para o economicamente hipossuficiente e para aqueles deixados à margem da sociedade. Ainda que notável o 


\section{PLURALISMO JURÍDICO COMO ALTERNATIVA EPISTEMOLÓGICA PARA A CULTURA DE DIREITOS HUMANOS DESDE O CONTEXTO LATINO-AMERICANO}

avanço em tema de prática dos direitos sociais, tem-se que os mesmos governos se tornaram "responsáveis por mega projetos que sonegam direitos de parcelas significativas da população" (VIOLA; PIRES, 2017, p. 286).

Dessa forma, têm-se direitos proclamados em tratados e cartas constitucionais, mas sonegados na vida, o que se agrava nos contextos periféricos dos Estados democráticos. Os direitos humanos, como direitos essenciais, promovem um discurso encantatório e ilusório, mas que não apresentam a efetividade devida, transformando esse fator, juntamente com suas funções e finalidades, em seus problemas mais aflitivos (MACHADO, 2017, p. 20). 0 problema central está em conhecer o real sentido do direito, não do que deveria ser feito com ele, mas o que é de fato realizado.

3 O PROBLEMA DOS DIREITOS HUMANOS: aportes da teoria crítica e da práxis emancipatória

O positivismo jurídico clássico teorizado pelo austríaco Hans Kelsen compreendia que algo, para ser considerado direito, deveria ter um núcleo mínimo de eficácia. No campo dos direitos humanos e fundamentais, pode-se dizer que houve uma promessa de realização ou meras aparências, que se firmaram na seara formalista e pouco transmigraram para a materialidade. Assim, o conjunto dos direitos humanos não tem por finalidade própria a resolução de conflitos humanos, como ocorre com as regras de direito material civil ou penal, mas sim uma ideia de fornecer suporte à dignidade humana aos direitos de cidadania e à democracia. A partir disso nasce a necessidade de se invocar a problemática sobre a efetividade prática desses direitos humanos, porquanto se trata do problema-eixo, nuclear, em torno do qual estão todas as reflexões teóricas e colocações práticas.

O problema posto fica mais evidente na medida em que, na realidade brasileira, a taxa de não efetividade dos direitos humanos é deveras alta. Nesse sentido, comentando a problemática do acesso à moradia adequada e de qualidade, Bruna Nogueira Machado Morato de Andrade $(2019$, p. 114-115) traz à tona os pormenores processuais do caso de reintegração de posse levada a cabo na denominada Vila Itália, uma comunidade situada no município de São José do Rio Preto, no oeste paulista. Segundo coloca, o ajuizamento da ação de reintegração de posse pelo citado município não apenas aclarou a institucionalidade da problemática de acesso aos direitos humanos, tal como desnudou marcas de preconceito junto aos moradores, vez que o poder público a eles se referia como "invasores" (MORATO DE ANDRADE, 2019, p. 115). Conforme a autora, "interessante notar que os moradores, segundo a municipalidade, não poderiam estar sendo instruídos", de modo que "além de não terem seus mínimos direitos fundamentais garantidos, têm que ser ignorantes e assim permanecerem" (MORATO DE ANDRADE, 2019, p. 115). 
Nesse contexto, têm-se direitos proclamados em tratados e cartas internacionais, mas sonegados na vida prática, o que se agrava nas periferias dos chamados Estados Democráticos de Direito. De acordo com Caio Granduque José (2011, p. 22), com base nas lições dos professores David Sánchez Rubio e Antônio Alberto Machado, menciona-se o efeito encantatório produzido pelos direitos humanos, o que significa afirmar a existência de um "efeito ilusionista, prestidigitador, falsificador ou fascinar que esses direitos produzem nos juristas, os quais se satisfazem com a retórica vazia que eles representam, ainda que em completo descompasso com a realidade material".

As ilusões produzidas pelos direitos humanos ao serem postos em cartas recheadas de termos e propostas sociais programáticas, assim como a mera formalização desses direitos, produziram uma espécie de cativeiro ou quadrado paradigmático, como posto pelo professor Antônio Alberto Machado (2017, p. 21). Enquanto obstáculo teórico, a cultura de direitos humanos é essencialmente formal e distanciada das tensões históricas que formularam o direito, de modo que todas as linhas de pensamento do direito contemporâneo se encontram fechadas, aprisionadas e com poder de rebeldia plenamente castrado no âmbito do cativeiro formalista. Na sequência, o plano político demonstra a existência de uma concepção liberal de direito e justiça, que não corresponde aos anseios das populações marginalizadas. Em terceiro lugar, no quesito econômico, a supressão de um Estado do bem-estar social na América Latina contribui deveras para a falta de distribuição de direitos, sob o argumento da falta de recursos para seu custeio e manutenção.

Sobre o tema, explica o professor Antônio Alberto Machado (2017, p. 21):

[...] a eficácia de tais direitos passa pela superação de nossa cultura jurídica essencialmente formalista; pela reelaboração dos objetivos, fins e valores do Estado liberal; e pela redefinição das relações entre o Estado e os setores que respondem pela produção econômica na sociedade capitalista. Estes, como se vê, são desafios teóricos, mas também políticos e econômicos. Natural, pois, que o problema da efetividade/inefetividade dos direitos humanos fundamentais não seja apenas um problema de juristas, mas, também, de outros atores sociais e políticos que se movimentam no plano histórico em torno e em luta pelos valores da democracia material e da justiça distributiva.

Em realidade, nenhuma das teorias desenvolvidas na história do direito conseguiu superar o quadrado paradigmático formalista, visto que não conseguem ultrapassar a ideia de que o direito é norma e que o método de pensamento que deve prevalecer, em uma sociedade capitalista e liberal, é o lógico-formal. O mesmo raciocínio é válido para as teorias pós-positivistas, já que também não conseguiram dar respostas satisfatórias ao problema da falta de efetividade dos direitos humanos, tal como não apresentaram propostas à solução dos obstáculos que produzem os altos graus de inefetividade. Foi apenas com a aplicação da teoria crítica, formulada nas pesquisas da Escola de Frankfurt, aos direitos humanos que se ensaiou uma tímida rebeldia contra o cativeiro formal que encampa esses direitos. 


\section{PLURALISMO JURÍDICO COMO ALTERNATIVA EPISTEMOLÓGICA PARA A CULTURA DE DIREITOS HUMANOS DESDE O CONTEXTO LATINO-AMERICANO}

Na América Latina - espaço em que o fracasso dos direitos humanos é especialmente visualizado, sobretudo por se tratar de um contexto de desigualdades e injustiças sociais -, a teoria crítica dos direitos humanos se aproxima constantemente da chamada filosofia da libertação, encabeçada pelo filósofo argentino Enrique Dussel, cuja proposta central é, a partir de uma base marxista adaptada à realidade sociopolítica latino-americana, inserir o continente na cadeia produtiva dos saberes, apresentar a história contra-hegemônica e a vítima enquanto sujeito negado e pessoa que vive concretamente a crise dos direitos humanos. Dessa forma, a teoria crítica dos direitos humanos, amoldada às problemáticas das sociedades latino-americanas, vem como um dos galhos do marxismo, adotando-se um viés interpretativo a partir do olhar da vítima - ou daquilo que o poeta mexicano Octavio Paz chamou de ninguneados ${ }^{6}$.

Contrariamente à concepção clássica arraigada nas escolas de direito brasileiras e latinoamericanas em geral, resultado do colonialismo jurídico europeu, de cunho burguês e liberal, que acentua os direitos humanos enquanto fruto das revoluções burguesas levadas a cabo preponderantemente no século XVIII, a teoria crítica aplicada ao contexto social e político da América Latina parte de dois princípios: a afirmação de que os direitos humanos possuem caracteres políticos, e não apenas teóricos e técnicos; e a concepção desses direitos como produto cultural das lutas sociais postas em prática por grupos marginalizados e historicamente excluídos da história hegemônica, contada pelos europeus.

Em primeiro lugar, deve-se partir da noção de que os direitos humanos possuem em sua gênese uma dimensão faceta, e não única e meramente teórica ou técnica, restrita à prática forense. Não por outro motivo é que se afirma que os problemas atinentes a esses direitos não estão restritos aos juristas, já que atingem outras áreas do conhecimento e da sociedade (MACHADO, 2017, p. 21), de modo que as violações dos direitos humanos ensinam, na prática, a significação que possuem enquanto em plena vigência. Tem-se que os direitos dos homens não podem ser dissociados do campo político: por exemplo, não há democracia sem respeito aos direitos humanos, assim como o inverso se faz verdadeiro.

Assim, além de preceito axiológico e teórico, vê-se que os direitos humanos possuem também uma dimensão política, pois não são frutos tão somente da paz, mas sim da luta, do conflito, do tumulto e da busca por emancipação social. Sob essa perspectiva, os direitos humanos aparecerem como mecanismos capazes de apresentarem um horizonte ${ }^{7}$ de sentido na busca por uma sociedade mais livre. Pensando a proposta política dos direitos humanos, Óscar Correas (2017) afirma que aqueles que estão do lado dos outros - dos vulneráveis - são condenados socialmente por tais lutas.

De acordo com o professor argentino: 
[...] los derechos humanos constituyen medios de defender bienes que han sido conquistados em la lucha contra los opresores. Son conquistas de la humanidad, pero en el tránsito hacia una sociedad mejor. Y por cierto que no es válido que ahora los opresores los usen para desactivar la lucha que los oprimidos deben continuar desarrollando contra su intransigencia ${ }^{8}$. (CORREAS, 2017, p. 410)

Em virtude das especificidades políticas, sociais, culturais e econômicas percebidas na história do continente latino-americano, tecer pensamentos sobre o movimento europeu de colonização e encarceramento do direito plural originário da América Latina, calado para dar espaço à compreensão monista do direito, exige também analisar sistemicamente as teses defendidas na esfera política, as leis que são aprovadas e quem são os atores e demais personagens que têm suas concepções de direito e justiça satisfeitas ou liquidadas pelo direito hegemônico.

$\mathrm{Na}$ margem contrária, para além da ideia de que os direitos humanos possuem uma dimensão política, situa-se a noção de que esses direitos não se conformam enquanto dados, senão sob a forma de construtos sociais, motivo pelo qual não se pode classificar como direitos humanos as meras declarações textuais, feitas à luz - ou sombra - do formalismo cego. Na verdade, como afirma 0 professor Joaquín Herrera Flores (2002, p. 26-27), "os direitos humanos são os meios discursivos, expressivos e normativos que pugnam por reinserir os seres humanos no circuito de reprodução e manutenção da vida, permitindo-lhes abrir espaços de luta e de reivindicação".

De fato, a grande jogada das teorias críticas do direito aplicadas aos direitos humanos no âmbito latino-americano é demandar um novo olhar sobre os problemas que afetam a efetividade material desses direitos, a partir de uma contextualização deles como resultados de lutas sociais pela dignidade humana. A característica principal da teoria crítica na América Latina é a busca dos direitos humanos na práxis, como luta de grupos marginalizados para a construção de uma história autêntica não há terceiro intermediando a luta, pois ela parte do próprio grupo que se organiza e reivindica.

A ideia central é romper com a perspectiva do assistencialismo estatal, já que concessões que não são de natureza emancipatória - que conduzem o sujeito à superação da imaturidade a partir de um processo racional crítico (DUSSEL, 1992) - não fazem parte da teoria crítica dos direitos humanos. A perspectiva emancipatória em direitos humanos significa que os povos dominados, postos à margem, devem estabelecer processos de luta social que visem alcançar o pleno exercício de seus direitos fundamentais, o que equivale à seguinte fórmula: prática social + compromisso de emancipação.

Nesse sentido, ao se falar nessa proposta emancipatória no continente latino-americano, 0 pluralismo jurídico se revela como elemento que tenta paralisar e fornecer uma descontinuidade à lógica tradicionalista em direitos humanos, de cunho conservador, monista e hegemônica, levada a cabo pelos interesses dos dominadores, em seus respectivos territórios dominados, como modelo de 


\section{PLURALISMO JURÍDICO COMO ALTERNATIVA EPISTEMOLÓGICA PARA A CULTURA DE DIREITOS HUMANOS DESDE O CONTEXTO LATINO-AMERICANO}

pensamento sobre esses direitos e sua consequente carga emancipatória, em face de uma sociedade na qual impera a razão das exclusões concretas e das inclusões abstratas.

\section{PLURALISMO JURÍDICO COMO ELEMENTO CENTRAL DAS LUTAS POR DIREITOS HUMANOS}

A construção cultural das bases teóricas e práticas do direito na América Latina a partir dos subsídios fornecidos pelos colonizadores, em grande parte portugueses e espanhóis, fez com que se carregasse socialmente o distanciamento da ideia de que os direitos humanos devem ser concebidos como processos de luta encabeçados por grupos sociais discriminados e historicamente excluídos de uma cidadania plena, revogando seu princípio de sujeito dos direitos humanos. Assim, racionalizar os direitos humanos sob uma proposta emancipatória significa basicamente retirá-los do âmbito da teoria tradicional, como direitos instituídos, advindos dos documentos constitucionais e tratados internacionais, para inseri-los na condição de direitos instituintes.

Afirmar que os direitos humanos devem ser instituintes, e não instituídos, como frutos dos textos normativos, significa defender a posição ventilada pela teoria crítica de que é urgente a necessidade de se romper com a concepção puramente positivista, estatista, formalista e pós-violatória oferecida pelos caminhos clássicos da cultura jurídica ocidental, notadamente dos Estados periféricos e antigas colônias europeias. Dessa forma, direitos humanos instituintes são aqueles que se constroem "a partir de prácticas sociales y acciones humanas que empoderan sujetos 9" (RUBIO, 2014, p. 254). Busca-se transformar os direitos humanos ao ponto em que deixam de pertencer única e exclusivamente às instâncias clássicas e atingem as práticas sociais.

Nesse viés, conforme o professor David Sánchez Rubio (2014, p. 254):

[...] derechos humanos tienen como referente básico la vocación de autonomía de los sujetos sociales como matriz de autonomía de los individuos o personas. Guardarían relación con la capacidad que el ser humano tiene y debe tener como sujeto para dotar de carácter a sus propias producciones en entornos que no domina completamente y, también, estarían vinculados con la disposición de denunciar y luchar contra cualquier situación que imposibilite esta capacidad de crear, significar y resignificar a las instituciones socialmente producidas $^{10}$.

Observar o passo a passo da montagem cultural dos direitos humanos e de seu grau de efetividade nas sociedades deixadas à margem de um direito com caráter emancipatório permite assinalar que as fagulhas que dão origem e efetividade prática aos direitos reivindicados são as lutas sociais. Citam-se como exemplo dessa emancipação jurídica em decorrência das lutas sociais as reivindicações postas nas vozes de movimentos sociais, como a classe trabalhadora ou o feminismo, já que, como afirma David Sánchez Rubio (2014, p. 248), "los actores sociales y los sujetos socio- 
históricos protagonistas [...] en sus luchas alcanzan una incidencia política y cultural que puede institucionalizar sus reclamos jurídicamente y con eficacia ${ }^{11 " .}$

$\mathrm{Na}$ América Latina, em virtude de suas especificidades políticas, culturais, jurídicas, sociais e econômicas, direitos humanos instituintes apenas são possíveis se houver uma alteração no marco cultural do direito, em grande parte herdado do colonialismo europeu, haja vista a composição de noções jurídicas, do objeto do direito, preexistentes com o novo entendimento advindo das metrópoles. Dentre as propostas contraculturais se encontra o pluralismo jurídico, que, especificamente no Brasil, ganhou maiores projeções a partir da obra do professor Antônio Carlos Wolkmer e sua proposta de pluralismo jurídico comunitário participativo. Não se olvidando da polissemia do termo em questão, de acordo com a tese desenvolvida pelo autor, o pluralismo jurídico deve ser compreendido como o meio pelo qual o direito se faz reconhecido pelas práticas aceitas em determinados grupos, em tempo e espaço específicos, de forma não restrita ou limitada pelo direito posto pelo Estado.

Sendo a categoria "pluralismo", segundo Norberto Bobbio, Nicola Matteucci e Gianfranco Pasquino (1998, p. 928), tudo aquilo relacionado à ideia de que a sociedade é composta por vários grupos ou centros de poder, isso nos permite afirmar que as muitas definições de pluralismo jurídico têm em comum entre si a proposta de negar que o Estado é o único feitor de normas jurídicas, dando especial prevalência aos usos e costumes locais sobre o rigorismo formal advindo do direito metropolitano. A propósito, assevera o professor Antônio Carlos Wolkmer (2001, p. 168) que o pluralismo jurídico pode ser traduzido como "a negação de que o Estado seja a fonte única e exclusiva de todo o Direito".

Portanto, pode-se dizer que o direito visto sob o paradigma do pluralismo está fundado na necessidade (e possibilidade) de existência de uma multiplicidade de fontes para o fenômeno jurídico, que não fique restrito unicamente às normas editadas pelo Estado. Trata-se de almejar uma substituição ético-social, que vá do poder instituinte oligárquico para o poder instituinte popular. Dessa forma, o primeiro, pautado em um modelo reacionário ou conservador de pluralismo jurídico - cuja missão é suspender e destruir direitos humanos, como retrato do novo capitalismo mundial, em que o Estado deixa de agir e se volta à desregulamentação, à desconstitucionalização dos direitos humanos, à desubjetivização dos atores e dos movimentos sociais - deve ser convertido no segundo, um pluralismo jurídico emancipatório, levado à prática pelos novos movimentos sociais ${ }^{12}$, que prezam pela afirmação e expansão dos direitos humanos, visando assegurar a efetividade dos direitos já consagrados nas cartas jurídicas ou reivindicar aqueles que fugiam da esfera oficial.

A proposta do pluralismo jurídico emancipatório, de orientação democrática, é fornecer novas perspectivas às práticas jurídicas, em contraposição ao monismo jurídico e como forma de incremento às relações sociais periféricas e dominadas, como a situação do sujeito da práxis enquanto 


\section{PLURALISMO JURÍDICO COMO ALTERNATIVA EPISTEMOLÓGICA PARA A CULTURA DE DIREITOS HUMANOS DESDE O CONTEXTO LATINO-AMERICANO}

ser histórico, concreto, coletivo e não privado. Nesse modelo, é necessária a legitimação dos novos sujeitos sociais, as coletividades, e a fundamentação das reivindicações nas necessidades humanas, nos direitos postos na ordem formal ou nos "novos direitos". Além disso, faz-se preciso a submissão das normas jurídicas, do direito em geral, ao controle popular, tal como a descentralização e democratização de um espaço comunitário participativo, governado a partir da ética da alteridade ${ }^{13} \mathrm{e}$ da busca de uma práxis libertadora.

Segundo o professor David Sánchez Rubio (2015, p. 131), partindo-se do fato de que os membros das sociedades periféricas, das quais inserimos a América Latina como um todo, não possuem sensibilidade sociocultural em relação aos seus direitos, bem como os desconhecem por completo, torna-se difícil defendê-los e reivindicar aqueles que ainda são lacunosos no sistema. Para ele, os povos devem ser educados em uma cultura jurídica pensada desde o movimento de fazer e desfazer os direitos humanos. Essa educação, seguindo a ótica da teoria crítica e da ética da libertação latino-americana, deve ser emancipatória, ou seja, não se trata de obrigar os cidadãos a decorarem os artigos de lei, sobretudo dos textos constitucionais, mas "hay que enseñar a partir de una praxis acompañada por teorías, que nos conviertan en personas más activas y efectivas a nível multi-escalar y desde una cultura de derechos humanos a tiempo completo y en todo lugar14" (RUBIO, 2015, p. 131).

Para que os direitos não sejam meras palavras e textos, distantes da perspectiva pluralista do direito, é preciso erigi-los à ordem de direitos multiescalares. Em primeiro lugar, as garantias jurídicas estatais, formadas pelas interpretações mais favoráveis à aplicação de garantias sociais e pelo uso não burguês de um direito (ainda que burguês). Em segunda posição, as garantias jurídicas não estatais, como o direito à produção jurígena a partir de grupos minoritários e socialmente excluídos, visando dar efetividade à proposta de pluralismo jurídico emancipatório. Por fim, as garantias sociais, pautadas na educação em e para os direitos humanos, feita de forma emancipatória, com 0 ganho de sensibilidade sociocultural.

$\mathrm{Na}$ linha de reconhecimento do pluralismo jurídico como elemento nuclear nas lutas pela efetivação prática dos direitos humanos, o professor Antônio Alberto Machado (2017, p. 161) compreende que a efetividade dos direitos fundamentais está intrinsecamente ligada à eleição das experiências de pluralidade como meios para o alcance dessa finalidade. Trata-se de pôr em prática as "manifestações jurídicas à margem da ordem vigente, especialmente no seio de grupos e movimentos sociais em luta pela inclusão e pela transformação das relações socialmente injustas a que estão submetidos". Daí ser correta a assertiva segundo a qual a adequação do pluralismo jurídico como instrumento para a superação da ideia monista de que o direito é apenas o criado nos parlamentos está em reconhecer o direito feito pela marginalidade. Ou seja, se o perfazimento do direito não se dá pela institucionalidade, deve-se fazer por meio da marginalidade, como "resposta à injustiça, ineficácia e 
esgotamento da legalidade liberal-individualista" (WOLKMER, 2001, p. 300) e, acrescentamos, como resposta à crise de efetividade dos direitos humanos.

Verifica-se que o pluralismo jurídico surge como alternativa à epistemologia clássica dos direitos humanos no contexto latino-americano, de rechaça do direito e das reivindicações produzidas pelos grupos historicamente excluídos, que visam acessar os direitos básicos negados. Evidentemente, o problema da inefetividade dos direitos humanos não está restrito aos espaços sociais das comunidades estatais periféricas, como a América Latina em geral, mas também atinge universos centrais, como a Europa ou a América do Norte - certamente mais desenvolvidos economicamente quando comparados com as regiões vítimas históricas da colonização predatória. Como coloca Machado (2017, p. 163), a ineficácia dos direitos humanos é verificada em espaços plurais periféricos e centrais, "em que se reproduzem situações de opressão e de desigualdade social e econômica, numa evidência de que o problema da inefetividade não é apenas cultural, nem religioso, nem étnico - e, sim, socioeconômico e político".

É certo dizer que o pluralismo jurídico aparece na linha de frente das lutas por direitos humanos no contexto social, político e cultural da América Latina. Por razões já postas sobre as especificidades e diferenças históricas, aprofundadas pelos movimentos de colonização - que atingem, inclusive, o âmbito jurídico -, vê-se que a missão precípua do pluralismo jurídico nesse espaço é alterar o foco de interpretação dos direitos humanos, para trazê-los para a perspectiva da vítima, que são as grandes coletividades vulneráveis, como a população negra, os indígenas e quilombolas, os periféricos, as mulheres, as crianças e adolescentes e as pessoas com deficiência. Evidente que esse giro hermenêutico não prejudica a ideia do pluralismo servir como contraproposta ao monismo, mediante reconhecimento do direito não estatal, erguendo à categoria de autênticos sistemas jurídicos aqueles produzidos pelos novos movimentos sociais, cujos melhores exemplos são aqueles relacionados à luta pela terra ou por moradias adequadas.

Desse modo, a luta por dignidade, inclusão e cidadania na América Latina constitui a práxis necessária ao processo de universalização dos direitos humanos, mediante reconhecimento de uma ordem jurídica plural emancipatória, assim como permite a quebra do monopólio estatal de produção do direito para dar abertura às reivindicações postas à margem da sociedade, dos excluídos e vitimizados.

\section{CONCLUSÃO}

As concepções clássicas sobre a origem e formação dos direitos humanos não prosperam de forma idêntica a partir do surgimento das correntes críticas, que põe em tela os principais problemas 


\section{PLURALISMO JURÍDICO COMO ALTERNATIVA EPISTEMOLÓGICA PARA A CULTURA DE DIREITOS HUMANOS DESDE O CONTEXTO LATINO-AMERICANO}

enfrentados no âmbito da militância por direitos humanos, dos quais se destaca a alta taxa de inefetividade desses direitos em sociedades periféricas - o que não elimina a ocorrência do mesmo fenômeno em sociedades centralizadas, e antes consideradas metropolitanas. Nesse sentido, 0 professor Antônio Carlos Wolkmer (2004, p. 13), ao comentar o histórico construtivo dos direitos humanos a partir da obra de Marx denominada "A questão judaica", assevera que "a ideia dos direitos humanos não é algo inato ao ser humano [...], mas fruto da luta contra o acaso do nascimento, contra os privilégios que a história, até então, vinha transmitindo hereditariamente [...]".

De fato, a cultura de direitos humanos construída na América Latina ao longo dos tempos, desde a colonização, é reflexo direto das estruturas institucionais baseadas nos interesses das metrópoles frente às colônias. Os documentos constitucionais produzidos no contexto latino-americano estão marcados não unicamente pelos resquícios do interesse das elites hegemônicas, como também trazem consigo o encarceramento dos direitos humanos junto ao positivismo jurídico, de ordenação formalista e burocrática. Isso leva à concepção de que nos satisfazemos com o efeito domesticador causado pelo direito meramente inserido na lei, esquecendo-nos, por força da ilusão causada por esse movimento, que os direitos na prática são dependentes de lutas.

Como proposta de reinvenção dos direitos humanos, sob a condição de produtos culturais das lutas sociais levadas a cabo no contexto latino-americano, o pensamento crítico sobre esses direitos tem por finalidade denunciar e colocar em xeque toda a estrutura tradicionalista, hegemônica e conservadora construída no entorno dos direitos humanos. Dessa forma, o papel da crítica é justamente subverter a ordem naturalizada e complacente dos homens frente a esses direitos, em condições de subordinação. Os direitos humanos, mais do que asseguradores de dimensões éticas, sociais e jurídicas, também ostentam o caráter político. Isso significa dizer que não basta somente verificar a inclusão formal desses direitos na lei, sendo preciso notar a luta por direitos e a quem eles beneficiam.

Nessa perspectiva de busca por alternativas epistemológicas ao formalismo juspositivista impregnado nos direitos latino-americanos, o pluralismo jurídico surge como meio de se permitir uma visão emancipatória sobre os direitos humanos, de uma dimensão reguladora não encarcerada da convivência social e comunitária. Assim, a concepção dos direitos humanos enquanto produtos culturais advindos das lutas sociais e individuais se mostra como elemento básico para melhor os compreender e conseguir inseri-los na prática de forma coerente. Com o pluralismo jurídico, não há uma efetiva superação da lacuna entre o direito teórico e o prático, conforme denunciado pela teoria crítica, mas com tal perspectiva é possível uma atuação dos sujeitos enquanto entes autônomos e diferenciados, no individual e no coletivo. 
O direcionamento de um pluralismo jurídico com potencial emancipatório, que vise fornecer reconhecimento e eficácia aos direitos humanos fundamentais, depende diretamente de uma transferência de poder, que saia do Estado e do direito oficial para recair sobre os coletivos vitimizados e oprimidos. Apenas assim é que haverá um direito que leve em consideração a efetivação de direitos humanos básicos e as relações humanas sob um viés não opressivo, libertador, sem hierarquizações e articulados a partir de dinâmicas pluralistas. Dessa forma, seria possível trazer às comunidades de vítimas o direito de serem "tratados como sujetos, pudiendo disfrutar de los derechos consolidados y establecidos desde esas lógicas liberadoras y emancipadoras, en contextos siempre contingentes, reversibles e inciertos ${ }^{15 "}$ (RUBIO, 2014, p. 248).

Portanto, à imagem e semelhança da introdução de novas perspectivas do direito plural nos documentos legais e constitucionais latino-americanos, a reinvenção dos direitos humanos sob a perspectiva do pluralismo jurídico emancipatório é essencial para compreendê-los como processos sociais, econômicos, culturais e políticos, que visam fomentar o surgimento de uma nova ordem em que sirvam como mecanismos de luta e de construção das novas subjetividades revolucionárias na América Latina, que venham desde abaixo, dos movimentos sociais, populares e dos povos esquecidos e marginalizados.

\section{REFERÊNCIAS}

ATIENZA, Manuel. Filosofía del derecho y transformación social. Madrid: Trotta, 2017.

BOBBIO, Norberto; MATTEUCCI, Nicola; PASQUINO, Gianfranco. Dicionário de política. Brasília: Editora Universidade de Brasília, 1998. v. 1.

CORREAS, Óscar. El derecho y los marxistas. Problemata: Revista Internacional de Filosofia, v. 8, n. 1, p. 403-413, 2017.

DUSSEL, Enrique. 1492: el encubrimiento del otro: hacia el origen del mito de la modernidad. Madrid: Nueva Utopia, 1992.

FAJARDO, Raquel Z. Yrigoyen. El horizonte del constitucionalismo pluralista: del multiculturalismo a la descolonización. In: GARAVITO, César Rodríguez (org.). El derecho en América Latina: un mapa para el pensamiento jurídico del siglo XXI. Buenos Aires: Siglo Veintiuno Editores, 2011. p. 139-159.

FLORES, Joaquín Herrera. Direitos humanos, interculturalidade e racionalidade de resistência. Sequência, Revista do Curso de Pós-Graduação em Direito da UFSC, v. 23, n. 44, p. 9-29, 2002.

GADAMER, Hans-Georg. Verdade e método: traços fundamentais de uma hermenêutica filosófica. Petrópolis: Vozes, 1997.

GALLARDO, Helio. Teoría crítica: matriz y posibilidad de derechos humanos. San Luis Potosi: Comisión Estatal de Derechos Humanos de San Luís Potosí, 2008. 


\section{PLURALISMO JURÍDICO COMO ALTERNATIVA EPISTEMOLÓGICA PARA A CULTURA DE DIREITOS HUMANOS DESDE O CONTEXTO LATINO-AMERICANO}

JOSÉ, Caio Jesus Granduque. 0 absurdo dos direitos humanos: reflexões a partir de Albert Camus. 0 Direito Alternativo, v. 1, n. 1, p. 7-33, ago. 2011.

MACHADO, Antônio Alberto. Elementos de teoria dos direitos fundamentais. São Paulo: Cultura Acadêmica, 2017.

MORATO DE ANDRADE, Bruna Nogueira Machado. 0 caso da Vila Itália: direito como luta e práxis transformadora. 2019. 185f. Dissertação (Mestrado em Direito) - Faculdade de Ciências Humanas e Sociais, Universidade Estadual Paulista "Júlio de Mesquita Filho", Franca, 2019.

QUIJANO, Aníbal. Colonialidad y modernidad-racionalidad. In: BONILLO, Heraclio (org.). Los conquistados: 1492 y la población indígena de las Américas. Bogotá: Tercer Mundo Ediciones, 1992. p. 437-449.

RUBIO, David Sánchez. Crítica a una cultura estática y anestesiada de derechos humanos: por una recuperación de las dimensiones constituyentes de la lucha por los derechos. Derechos y Libertades, n. 33, p. 99-133, jun. 2015.

RUBIO, David Sánchez. Derechos humanos instituyentes, luchas sociales y acciones cotidianas. Revista Jurídica da Escola Superior do Ministério Público de São Paulo, São Paulo, v. 6, p. 243268, 2014.

SHIRLEY, Robert Weaver. Antropologia jurídica. São Paulo: Saraiva, 1987.

SILVA, Geyson Gonçalves da. Pluralismo jurídico, ética da libertação e a construção de uma nova cidadania. 2002. 180f. Dissertação (Mestrado em Direito) - Centro de Ciências Jurídicas, Universidade Federal de Santa Catarina, Florianópolis, 2002.

VELASTEGUÍ, Marena Briones. Un triple punto de partida. In: TEJADA, Francisco Cevallos (Coord.). Educación y buen vivir: reflexiones sobre su construcción. Quito: Contrato Social, 2012. p. 33-42.

VIOLA, Solon Eduardo Annes; PIRES, Thiago Vieira. Direitos humanos e sociedade: para além do liberalismo. In: RODINO, Ana Maria et al. (org.). Cultura e educação em direitos humanos na América Latina. João Pessoa: CCTA, 2016.

WOLKMER, Antônio Carlos. Marx, a questão judaica e os direitos humanos. Sequência, Revista do Curso de Pós-Graduação em Direito da UFSC, v. 25, n. 48, p. 11-28, 2004.

WOLKMER, Antônio Carlos. Pluralismo jurídico: fundamentos de uma nova cultura no Direito. 3. ed. São Paulo: Alfa Omega, 2001.

\section{Notas}

1 No documento constitucional boliviano, em especial, a ideia de bem viver (buen vivir ou suma qamaña) aparece como base fundamental do Estado, na seção em que se fala sobre princípios e finalidades da existência do ente estatal, o que leva à conclusão primária de que se trata de um princípio ético-moral de uma sociedade reinventada sob a base do pluralismo jurídico. Portanto, a proposta do povo boliviano ou equatoriano ao inserir em suas constituições o conceito de bem viver é trazer à tona os princípios clássicos dos direitos humanos, como a igualdade, a dignidade da pessoa humana, a liberdade do homem, o respeito, a equidade social, a realização da justiça social e dos direitos humanos em geral. Nesse 
mesmo sentido, resta evidente que o neoconstitucionalismo latino-americano leva em consideração a tradição de seus povos, porquanto, sobretudo nesses países, os documentos foram construídos a partir das ingerências dos grupos histórica e socialmente excluídos, como os indígenas. Conforme aponta Marena Briones Velastégui (2012, p. 36), o bem viver constitucional "Representa, reflete, recorre, recria uma maneira de pensar e ver o mundo, um modo de organizar 0 conhecimento sobre o mundo. É a concepção ancestral andina de vida que se mantém em vigor em muitas comunidades indígenas até hoje".

20 antropólogo do direito Robert Weaver Shirley (1987, p. 80), ao comentar a condição colonial do Brasil, cujas similaridades com o contexto de colonização portuguesa sobre a América Latina eram notórias, diz que "[...] Portugal não tencionava trazer justiça ao povo ou mesmo prestar serviços mais elementares a sua colônia. Essa desvinculação entre 0 Estado e a população é um tema constante na história brasileira. Direito que aqui existia era o dos coronéis, as leis da elite agrária, que embora basicamente uma forma do direito consuetudinário português do século XVI. [...] Ao longo dos séculos, grandes áreas do Brasil central foram povoadas com estas pequenas comunidades rurais, em grande parte excluída das leis das cidades e da economia nacional e internacional".

3 Tradução livre: 0 pluralismo jurídico, como forma de coexistência de vários sistemas normativos dentro de um mesmo espaço geopolítico, ainda que em sua forma colonial subordinada, não era admissível para a ideologia do Estado-nação. 0 Estado-nação monocultural, o monismo jurídico e um modelo de cidadania censitária (para homens brancos, proprietários e ilustrados) foram a coluna vertebral do constitucionalismo liberal do século XIX na América Latina. Um constitucionalismo importado pelas elites crioulas para configurar estados à sua imagem e semelhança, com exclusão dos povos originários, dos afrodescendentes, das mulheres e das maiorias subordinadas [...].

${ }^{4}$ No contexto de colonização da América espanhola, consideram-se crioulos os descendentes de espanhóis - portanto, brancos - nascidos fora da Europa, sendo grandes proprietários de terra e comerciantes.

5Tradução livre: Por um lado, concordamos com a importância dos direitos humanos, o efeito positivo e encantador que eles têm porque servem simbolicamente para legitimar a justiça dos estados civilizados, constitucionais e democráticos. Discursivamente, quase todos estão convencidos do quão necessários são para que princípios como dignidade humana, liberdade e igualdade sejam garantidos em qualquer comunidade que os respeite. Mas, por outro lado, sabemos como é difícil cumpri-los no dia a dia, na prática, e, o que é pior, que eles sejam garantidos em certos espaços sociais, como na esfera doméstica ou nos mundos de produção, trabalho e/ou mercado.

${ }^{6}$ O termo é tomado para se referir às pessoas cuja existência é socialmente apagada, de forma voluntária, ou simplesmente ignorada diante da complexidade das relações sociais travadas diariamente.

${ }^{7}$ Nossa concepção do termo segue a ideia fenomenológica apresentada pelo filósofo alemão Hans-Georg Gadamer (1997, p. 327), para quem "O conceito de horizonte deve aqui ser retido porque ele exprime a elevada amplitude de visão que deve ter quem compreender. Adquirir um horizonte significa aprender sempre a ver além do que está próximo, demasiado próximo, não para afastar o olhar, mas para melhor ver, num conjunto mais vasto e em proporções mais justas". Dessa forma, os direitos humanos se comportam como uma espécie de fim, que não podem ser reduzidos a meros meios ou instrumentos.

8 Tradução livre: [...] os direitos humanos constituem meios de defesa de bens conquistados na luta contra os opressores. São conquistas da humanidade, mas na transição para uma sociedade melhor. E certamente não é válido que os opressores agora os usem para desativar a luta que os oprimidos devem continuar a desenvolver contra sua intransigência.

9 Tradução livre: a partir de práticas sociais e ações humanas que empoderem sujeitos.

10 Tradução livre: [...] direitos humanos têm como referência básica a vocação de autonomia dos sujeitos sociais como matriz de autonomia de indivíduos ou pessoas. Estariam relacionados à capacidade que o ser humano tem e deve ter como sujeito para dar caráter às suas próprias produções em ambientes que ele não domina completamente e, também, estaria ligado à disposição de denunciar e lutar contra qualquer situação que impossibilite essa capacidade de criar, significar e ressignificar instituições produzidas socialmente.

11 Tradução livre: os atores sociais e os sujeitos protagonistas socio-históricos [...] em suas lutas alcançam uma incidência política e cultural que pode institucionalizar juridicamente e com eficácia suas reivindicações.

12 Segundo Geyson Gonçalves da Silva (2002, p. 72), em dissertação sobre o tema pluralismo jurídico e cidadania, os novos movimentos sociais (NMS) "buscam alterar a estrutura política existente, apostando numa nova percepção da sociedade com fundamento na participação direta e organizada de diversos setores sociais atingidos diretamente pela crise instalada. 


\section{PLURALISMO JURÍDICO COMO ALTERNATIVA EPISTEMOLÓGICA PARA A CULTURA DE DIREITOS HUMANOS DESDE O CONTEXTO LATINO-AMERICANO}

Mais ainda, os 'Novos Movimentos Sociais' questionam a estrutura do próprio Estado nacional, incapaz de responder, através do já antiquado sistema representativo, aos anseios de mudanças e participação encampados pelos NMS's".

${ }^{13}$ Se 0 outro é invisibilizado e diminuído, fazendo-se menção aqui aos grupos vulneráveis e minoritários, a ética da alteridade tem por finalidade produzir e reproduzir a atuação do indivíduo inferiorizado na sociedade pluralista.

14 Tradução livre: devemos ensinar a partir de uma práxis acompanhada por teorias, que nos convertam em pessoas mais ativas e efetivas a nível multi-escalar e desde uma cultura de direitos humanos em tempo integral e em todo lugar.

15 Tradução livre: tratados como sujeitos, podendo desfrutar dos direitos consolidados e estabelecidos a partir dessas lógicas libertadoras e emancipatórias em contextos sempre contingentes, reversíveis e incertos. 